\title{
Slippery Bows and Slow Circuits
}

\author{
John Richards / jrich@dmu.ac.uk \\ Music, Technology and Innovation Research Centre, De Montfort University, Leicester, UK
}

\begin{abstract}
This article is based on a keynote lecture given at the 51st International Musicological Colloquium, Masaryk University, Brno, that was part lecture, part performance. The lecture was presented in the style of a series of statements with performance elements, of which the order was improvised. In response to the conference call and with reference to DIY electronic music, the article covers the topics of: the relationship between music and technology; what could be considered as post-technological music; technologically generated, supported, or mediated music; and issues arising that relate to virtuosity. The article also discusses the impact of neo-Luddism and the Slow Movement on music technology and Nam June Paik's declaration 'I make technology ridiculous'. Examples of work by the author (Dirty Electronics), Gijs Gieskes, John Bowers, and Leonardo Ulian are also discussed.
\end{abstract}

\section{Keywords}

DIY electronic music, instrument, music technology, slow technology, oblique strategies, post-optimal, neo-Luddite, object-orientated, music of things, ethnography, virtuosity 


\section{Slippery bows and slow circuits}

A stick, a piece of string: a bow. Take an old motor from a printer or electrical appliance, connect a jack to the motor terminals, and turn, bow the motor and amplify. ${ }^{1}$ Each motor has its own 'voice' and characteristic. It is not just that the motor when amplified produces sound, but how it is played that goes towards forming this character. This is not a music technology of efficiency and upgrades. The primitive bow and the never-intended-to-make-sound motor present instrumental and musical challenges and questions to the player. A struggle of sorts is presented between instrumentalist and instrument, and man/woman and machine. How can a music be found through this approach and these objects? The motor creates an ambiguity in terms of how it should be played within a musical context. As William Gaver remarks in relation to design and human computer interfaces: "Ambiguity can be frustrating, to be sure. But it can also be intriguing, mysterious, and delightful."

A circuit in DIY electronics is 'slow' in its method of design and construction. Through slowing down the making there is more time for reflection and an opportunity to re/connect with 'musical' stuff. Within DIY electronic music there has been a form of arts and crafts revivalism: of human-scale and self-sufficiency. Hand-made and crafting ethoses prevail over mass produced and industrialised processes. Lars Hallnäs and Johan Redström take up a similar theme in their paper Slow Technology - Designing for Reflecti$o n{ }^{3}$ There are also parallels in general with the Slow Movement, a counter movement against the information superhighway and high-speed communications brought about by technology and expressed by Carl Honoré in his book In Praise of Slowness. ${ }^{4}$ I have made such slow circuits in, for example, the piece Hope (2011) where participants make circuits that produce a single grain of sound over a weekend. It is only at the end of the drawn-out process and through a collective effort that the circuits are amassed and sounded together to create a texture. ${ }^{5}$

\section{Post-optimal technological object}

Digital cameras, electric kettles, mobile phones and home computers have reached a design stage where, in many instances, optimisation of technical functionality is no longer a priority. Anthony Dunne in Herzian Tales presents the idea of the post-optimal

1 From the score Motor Music, John Richards, 2015.

2 GAVER, William W., BEAVER, Jacob, and BENFORD, Steve. Ambiguity as a Resource for Design. Proceedings of the SIGCHI Conference on Human Factors in Computing Systems, 2003, vol. 5, no. 3, p. 233.

3 HALLNÄS, Lars, and REDSTRÖM, Johan. Slow Technology - Designing for Reflection. Personal and Ubiquitous Computing, 2001, vol. 5, no. 3, p. 201-212.

4 HONORÉ, Carl. In Praise of Slowness: How a Worldwide Movement is Challenging the Cult of Speed. San Francisco: HarperSanFrancisco, 2004.

5 Hope was created for the Festival of Britain 60th Anniversary, Festival Hall (Clore Ballroom), 13-14 August, 2011. 
technological object. ${ }^{6}$ Dunne argues the challenge for designers of these objects now lies "in the realms of metaphysics, poetry, and aesthetics"; 7 and design research should explore "a new role for the electronic object, one that facilitates more poetic modes of habitation". ${ }^{8}$ These concerns may also apply to music and the rather nebulous field of music technology. Death by a thousand music apps: a sampler, favourite virtual synth or mobile studio. Music technology brought to the fingertips. Record in hi-resolution any time, any place, anywhere. No limits! But to what musical ends? It is not necessarily a question of being anti-technology, a kind of digital Romanticism, but thinking post-optimal towards a more critical use of and relationship with technology.

Bertolt Brecht in his essay The Radio as an Apparatus of Communication, criticised the one directionality of radio and its means of distribution rather than communication; ${ }^{9}$ whilst Nam June Paik railed against the passive consumption of television and set out to critique this in works such as Candle TV (1975) and TV Buddha (1976). Here both Brecht and Paik aim to question our relationship with technological objects such as the radio and television. Moreover, in Paik's work The Selling of New York (1972) a voice on the television asserts: "The advent of the cybernetic age and post-industrial society has changed everything ... Our problem is not how to produce but how to consume." 10 The idea of high consumption yet low quality content is a recurring theme in Paik's work. There are similarities between the views expressed by Paik and that of Anthony Dunne with an importance placed on the metaphysics and poetics of the everyday common-allgarden technological objects and thinking beyond mere consumption. A more recent work by Leonardo Ulian takes up this mantle. Ulian's Now and Forever (2013), where a mini LCD screen with a video of a flame is put inside an old gas lantern, bears connections with Paik's candle and television pieces. So what of a very different kind of music technology: unplayable or uncontrollable instruments, disfunctionality, sound devices that do not fit under the hand, oblique strategies (to use an Enoism), assemblages and things with no boundaries and demarcations, technologies of the imagination? Bad design? Maybe, but provocations too towards the very things that music is made of and with. ${ }^{11}$

6 DUNNE, Anthony. Hertzian Tales: Electronic Products, Aesthetic Experience, and Critical Design. The MIT Press: Cambridge, Massachusetts, 2005.

7 Ibid., p. 20.

8 Ibid., p. 20.

9 BRECHT, Bertolt, and WILLETT, John. Brecht on Theatre: The Development of an Aesthetic. New York: Hill and Wang, 1964.

10 PAIK, Nam J., and YALKUT, Jud. Suite 212 [video]. New York: Electronic Arts Intermix [distributor], 1975 [re-edited 1977].

11 Throughout the article there are references to oblique strategies in relation to Brian Eno's and Peter Schmidt's Oblique Strategies (1975). 


\section{I make technology ridiculous}

Nam June Paik in an interview with Calvin Tompkins for Edited for Television (1975) states: "I make technology ridiculous". ${ }^{12}$ Picking up on this point, Leigh Landy in 'I Make Technology Ridiculous': the Unusual Dialectics of June Paik, also argues that Paik places instruments "on trial". ${ }^{13}$ The ideas of instruments on trial and the ridiculing of technology (instrument) are not exclusive to Nam June Paik. These ideas are also evident within the Fluxus movement in general where the violin and piano in particular fall victim to smashing, deconstruction and ridicule. George Maciunas' works Solo for Violin (For Sylvano Bussotti) (1962), and 12 Piano Compositions for Nam June Paik being good examples.

There are also precedents for instrument on trial in, for example, Helmut Lachenmann's Guero, for piano (1969/70) that sets out to discard the tropes, norms and accepted repertoire associated with the instrument. Lachermann plays on the similarities between the percussion instrument, the guero, and the piano keyboard: by scrapping the hand across the surface of the piano keyboard, a percussive sound, resembling that of the guero, can be made. The work goes beyond the use of extended playing techniques. It tries to look at the piano in a new light, taking an oblique strategy towards playing and engaging with the instrument. The piano keyboard as guero also presents a ridiculous paradigm. Lachenmann's deconstruction of instrument and what he termed as 'musique concrète instrumentale' is also found in his work Pression, for one cellist (1969). The playing of the cello is looked at 'inside out' with the cellist bowing the body of the cello, 'playing' the bow with hand, tapping all parts of the cello with the bow and hands, and rubbing strings with the hands. Such radical calls to readdress and trial musical instrument are also found in the seminal works of John Cage's Concert for Piano and Orchestra (1958) and Mauricio Kagel's Acustica (1968-70). Furthermore, Brian Eno and Peter Schmidt in their Oblique Strategies (1975) - a set of instruction cards for artists and musicians to aid lateral thinking and subtitled "Over One Hundred Worthwhile Dilemmas" - do not put instruments on trial as such, but offer ways in which an instrument may be approached or played. Examples of these strategies include: "Consider different fading systems", "(Organic) machinery", and "Look at a very small object, look at its centre". ${ }^{14}$

12 PAIK, Nam J., CONNOR, Russell, and TOMPKINS, Calvin. Nam June Paik: Edited for Television [TV], Produced by the TV Lab at WNET/Thirteen (VTR series), 1975.

13 LANDY, Leigh, and GRAEVENITZ, Antje von. 'I Make Technology Ridiculous': the Unusual Dialectics of June Paik. Avant Garde 7, 1992, p. 87.

14 ENO, Brian, and SCHMIDT, Peter. Oblique Strategies: Over One Hundred Worthwhile Dilemmas. [Place of publication not identified]: [publisher not identified], 2001 [original publication 1975]. 


\section{There should be no music technology}

I recently interviewed pioneer of computer art Frieder Nake. ${ }^{15}$ In preparation for the interview, I read and re-read some of his writings including his provocative article There Should Be No Computer Art. ${ }^{16}$ The tenet of this article is that technology - specifically the computer - not only serves artists but also the market, and from this, artists play a role "... in providing an aesthetic justification of and for bourgeois society." 17 Nake is adamant that: "Computers can and should be used in art in order to draw attention to new circumstances and connections and to forget 'art'." ${ }^{18}$ He argues that it is not technology per se that should be of value but the semantic information that technology or media can carry. It is on the socio-political ramifications of technology that he places importance. So if Nake's argument is extended to musicians: should there be no music technology? Should musicians be more critical of the means of production of music?

Nake's scepticism of technology is shared by a movement known as the neo-Luddites. This movement takes its name from a group of nineteenth-century weavers from the north of England who were opposed to the introduction of technology and industrialisation within their profession. Luddite has become a derogatory term for someone who is technologically naïve, a technophobe, and reluctant to what could be viewed as progress. However, the Luddites were not anti-technology. They were concerned with working conditions and job losses and the social impact brought about by new machinery and industrial processes. Kirkpatrick Sale in Rebels against the future: the Luddites and their war on the Industrial Revolution: lessons for the computer age highlights the plight of Luddites and how their concerns are still relevant in a post-industrial, technological society, and hence the neo-Luddites. ${ }^{19}$ This view is taken even further by Chellis Glendinning who argues that "Technology has failed Humanity" and that we have become "Barraged by Technology". ${ }^{20}$ In his influential book, Future Shock, Alvin Toffler, who died this year, also warned that the rise of technology would result in 'information overload'. ${ }^{21}$ Such movements and authors have signalled the importance of being ever more critical and ever more questioning of the role of technology within society, a criticism and questioning that should be at the heart of a music of technology. To conclude this statement I recall the words of Frank Malina who said: "I believe the most important benefit to be expected from the use of computers by artists will be sociological." 22

15 Frieder Nake interviewed by John Richards, Bremen, Germany, 29 September, 2016.

16 NAKE, Frieder. There Should Be No Computer Art. Bulletin of the Computer Art Society, London, p. 18-21.

17 Ibid., p. 18.

18 Ibid., p. 19.

19 SALE, Kirkpatrick. Rebels against the future: the Luddites and their war on the Industrial Revolution: lessons for the computer age. Reading, Mass: Addison-Wesley Pub. Co., 1995.

20 See GLENDINNING, Chellis. Notes Toward a Neo-Luddite Manifesto. Utne Reader, March/April, 1990.

21 TOFFLER, Alvin. Future Shock. New York: Random House, 1970.

22 MALINA, Frank J. Comments on Visual Fine Art Produced by Digital Computers. Leonardo, 1971, vol. 4, no. 3, p. 264. 


\section{The Music of Things}

My use of the term music of technology, or insistence on the using 'of' technology, stems from my writing of a chapter titled The Music of Things. ${ }^{23}$ Through the practice of DIY electronic music, my idea of musical instrument has broadened to include objects and things, which can also be technological. An object, or more specifically a sound object, implies some kind of autonomy and self-containment. It is clearly demarcated by its form and structure and has what could be considered an identity. Objects, by their very nature, may dictate certain conditions. I have previously written about an object-orientated approach to music making where the 'object' reveals the music. ${ }^{24}$ This approach can be seen to take shape in the philosophy of John Cage. Cage's discussions with the filmmaker Oscar Fischinger illustrating this point. ${ }^{25}$

The music of 'things', on the other hand, infers a music where instrument is not clearly defined in the traditional sense and may constitute disparate elements that juxtapose and contrast. The nature of this music revolves around the notion of instrumental flux, modularity and 'versioning'; and with this comes an emphasis on interconnections and relationships. The relationship between the things - including the organiser (the player) - potentially becomes of greater importance than the things themselves. The very nature of making stuff opens up possibilities for making music in a new way. It is through the making of circuits and electronic sound devices that an affinity with the concept of the 'music of things' becomes more pronounced. Sound-making begins with a collection of bits-and-pieces: in the technological realm electronic components and wire. The idea of musical instrument then becomes emergent and embryonic. Infra-instrument is a term used by John Bowers and Phil Archer to describe such instruments that are somehow not fully formed or sub-instruments. In the making of an infra-instrument the authors ask to: "Investigate temporary assemblies of stuff". ${ }^{26}$

Technological and non-technological things that are wired, sounded, re-constituted or contrasted present a music technology of a very different kind. Gijs Giesekes, with his 'houtje touwtje' (small sticks and string) approach that is, for example, found in his works Maglevdrummer (2016) and vu perc seq1a (2016), explores unlikely technological and material relationships, forming new synergies and sound-making references. John Bowers' OhmMy-God (2007) reduces musical instrument to a bowl of assorted electronic components, battery, probes and resulting voltages; whilst Martin Howse's Earthvoice (2015) seeks to find connections between the earth, code, software and technology. Emergent and embryonic instruments and an emphasis on making as a critical part of live performance can also be found in the works of the groups Loud Objects and the Breadboard Band.

23 Chapter and book in progress with Leigh Landy, 2016.

24 RICHARDS, John. Shifting Gender in Electronic Music: DIY and Maker Communities. Contemporary Music Review, 2016, vol. 35, no. 1, p. 40-52.

25 CAGE, John, and CHARLES, Daniel. For the Birds: John Cage in Conversation with Daniel Charles. Boston, MA and London: Boyars, 1981, p. 68.

26 BOWERS, John, and ARCHER, Phil. Not Hyper, Not Meta, Not Cyber but Infra-Instruments. Proceedings of the International Conference on New Interfaces for Musical Expression (NIME), Vancouver, BC, Canada, 2005, p. 6. 


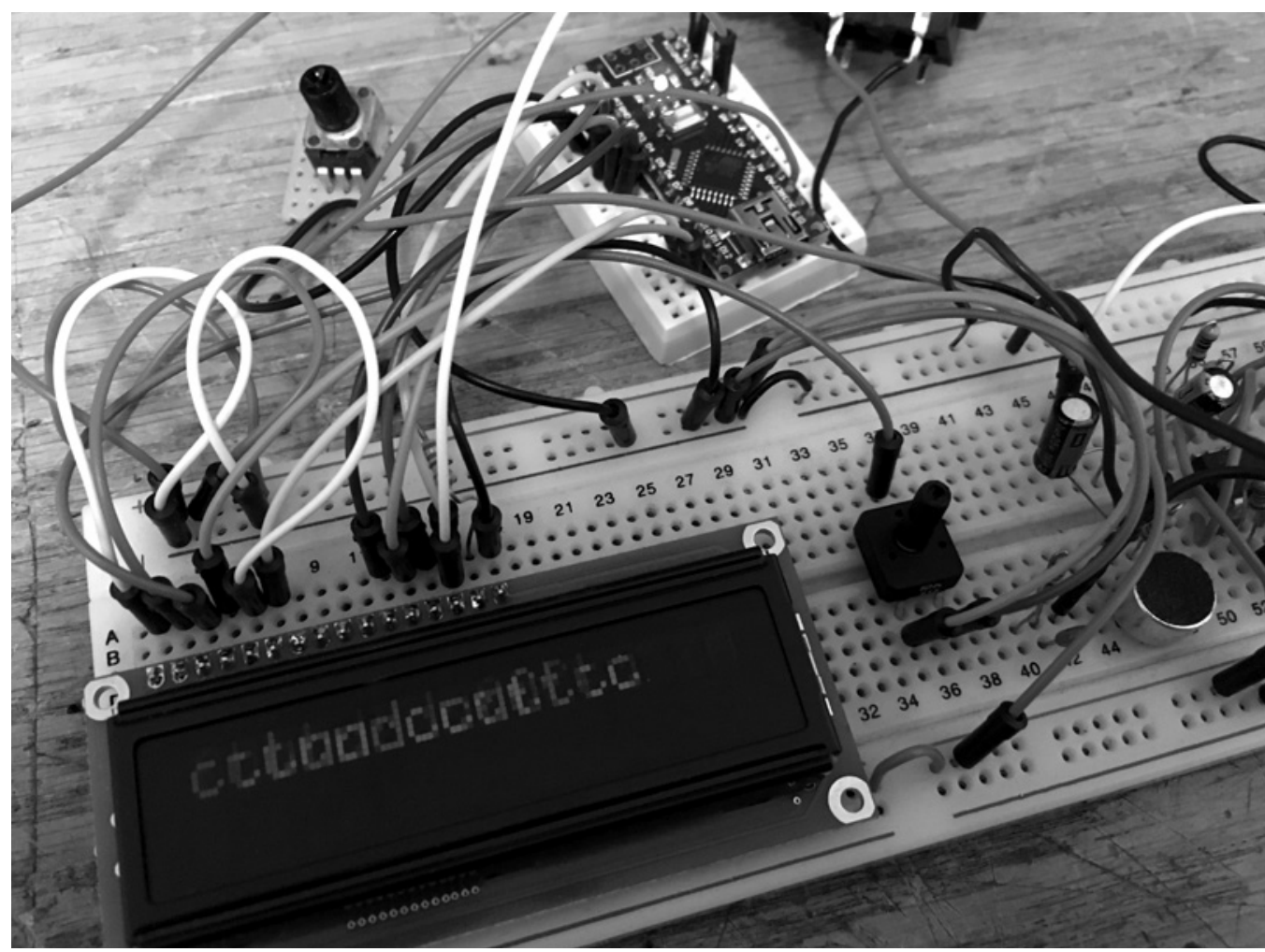

Fig. 1 Computer as text as computer 1

LCD screen and circuit as teleprompter

\section{Computer as text as computer 1}

Computer as text as computer 1 is an example of exploring the relationship between technology and its 'player'. ${ }^{27}$ In this instance, a liquid crystal display (LCD) becomes a makeshift teleprompter and by manipulating various parameters of the teleprompter there is a deliberate attempt to influence how text may or may not be recited. The teleprompter adopts a kind of materialism that contributes to the manner and delivery of the script. Below is the text/code used in the keynote lecture along with performance directions in square brackets.

Scrolling text, teleprompter for LCD screen and microprocessor 'object'. A camera is used to project an image of the LCD onto a large screen.

char message[] $=$ [set the speed of text scrolling and the brightness of the LCD so that the text can be easily viewed and read at a moderate pace] ("This talk is about not only how we shape technology, but also how technology shapes us. The LCD screen and its 
live streaming are illustrative of the frailty of media, technology being not quite what is and how my performance is altered - impaired or enhanced - through the prism of technology. I can start to play with the speed of text scrolling [gradually increase the speed of the text scrolling]. Can I keep up? The words are becoming a jumble of letters flowing into each other each other each other each other each other each other each other each other each other each other each other each other [a tempo]. Or can I change the parameters of the display to affect the screen and my voice? [reduce and increase the brightness of the LCD] I have mannerisms, idiosyncrasies in my speech, and also what could be considered technoisms [reset brightness]. You will be glad to hear that I will not present all of my talk in this manner.");

\section{Savignyplatz Berlin 1994}

Whilst an exchange student in Berlin, I would seek out and hunt down jazz concerts in small clubs, although I am not really sure if I even liked 'jazz'. The point of interest in such music lay in witnessing the struggle between performers (within a group) and performer and instrument and the process of 'finding' the music. This was also something both the performers and audience were actively involved in. As a listener, I was less concerned with the sound and 'musical' output and relished the procedural and, what could be loosely described as, relational aspects of the music. Cornelius Cardew in his seminal text Towards an Ethic of Improvisation also posits: "Who can be interested purely in sound, however high its 'fidelity'? Improvisation is a language spontaneously developed amongst the players and between players and listeners. Who can say in what consists the mode of operation of this language?". ${ }^{28}$ This point is also substantiated by Derek Bailey who has remarked that the focus for many jazz musicians and improvisers "is probably more on means than ends." 29 This quest for discovery, exploring unchartered territories and processes remains central to my/the concept of a music of technology.

Technology is often held up as a means to liberate humankind, providing labour and time saving solutions. In music technology this could be a mixing console, where all of the settings can be memorised and recalled; or having the choice and ability to search for pre-recorded sounds and samples. But this is something I chose to confront through technology in music. The essence lies in not making things easier, for example, playing an instrument that is 'easier' to play or designed to be ergonomic, but harder. There must be toil, physically and mentally. Much of my endeavour as a musician working within DIY electronic music has circled around creating sound making situations, instruments, things where a tabula rasa exists. There is a fundamental alignment between the practice of improvisation and DIY electronic music in that both have the capacity to occupy the realm of the unknown and require things - both abstract (musical) ideas and physical artefacts - to be built.

28 CARDEW, Cornelius. Treatise Handbook. London: Peters, 1971, p. xx.

29 BAILEY, Derek. Improvisation: its nature and practice in music. New York: Da Capo Press, 1993, p. 142. 


\section{Ethnomusicology vs ethnographic music technology}

I had a great deal in common with a friend when studying music at university. We shared many ideas and had a seemingly inexhaustible hunger to find new things within and through music. However, our musical paths appeared to take quite different routes. I became fascinated with electronic sound and its potential; whilst he became an ethnomusicologist specialising in the shaman ritual percussion music of South Korea. It often perplexed me that we started out on the same journey, but apparently ended up at different destinations. But the more I have reflected on this, the more I saw overarching similarities in our pursuits. Both of us sought to find the 'new' that fell outside the accepted musical canon; one through a different culture, the other through technology. Once the allure of the 'emperor's new clothes' had subsided, I became more interested in developing a critical awareness towards technology. The technology, or more specifically the things I was making music with, served as a vehicle to observe culture, they way we live, the way we relate or not to things around us, and in many respects I too became an ethnographer. I did not seek to impose preconceived ideas upon the technology that I was working with, but explored the technology from the ground up, seeing, or hearing what it would reveal. I was not simply a 'user' of technology.

The fields of human computer interaction (HCI) and interactive music place an emphasis on interaction. There is also a music technology of 'interface' epitomised by the NIME community. ${ }^{30}$ Yet I propose there is a very different type of music that relates to technology: that of reflection, observation and criticism. A natural home for this, and what could be called ethnographic music technology, would appear to be in DIY electronic music. In my own work as Dirty Electronics, I have often argued that workshops and building circuits serve as a form of analysis or observation of the materials for sound making and their musical potential. ${ }^{31}$ And how such making conditions offer an opportunity to create new relationships and stories with material objects. There is also how this 'way of doing' related to DIY electronic music cultivates a specific culture, and relationships are fostered between maker and maker. I have created situations that involve some kind of field-like work, such as the Ugly Weekender (2015) where making and performance coalesced around a pre-event brief and electronic circuits were built in candlelight to see how such conditions influenced the making of circuits and resulting music. ${ }^{32}$ One Knob to Rule Them All, a collaborative research project between Newcastle University and De Montfort University, Leicester also serves as an example of this type of curated research. ${ }^{33}$

30 New Interfaces for Musical Expression (NIME) is an annual international conference focusing on musical interface design - http://www.nime.org

31 RICHARDS, John. Beyond DIY in Electronic Music. Organised Sound, 2013, vol. 18, no. 3, p. 274-281.

32 FASS, John, and RICHARDS, John. Dirty Electronics Weekender [blog], 2015. https:/ / dirtyelectronicsweekender. wordpress.com [accessed on 1/1/2017]

33 BOWERS, John, et al. One knob to rule them all: reductionist interfaces for expansionist research. Proceedings of the International Conference on New Interfaces for Musical Expression (NIME), Brisbane, Australia, 2016, p. 433-438. 


\section{Computer as text as computer 2}

Computer as text as computer 2 is concerned with the idiosyncrasies, nuances and glitches of specific computer hardware and its software. ${ }^{34}$ Perhaps more specifically, the idea is to use a piece of software in a way it was not originally intended and to find the 'edges' of the functionality of the software to subvert and make ridiculous the process of text to speech. For example, is it possible to create text to song from text to speech software: the making of sound/music from synthesised vocal utterances? This calls for a fundamental reappraising of the software, and where computer hardware and software become can be viewed more holistically as instrument. Comparisons can be drawn here with Hans Kock's series of works Computer as Musical Instrument where the 'materiality' of computer hardware is a central theme.

\section{Computer as text as computer 2}

For Mac TextEdit and TextEdit Speech Function

This is computer as text as computer 2.

Can I make sounds instead of just reading separate letters? This is my glitch sound. dishjkj! And again. dishjkj! If I miss out the i, it becomes something else and I read separate letters: dshjkj. I cannot 'sing'! And my algorithm sometimes won't let me 'sound'. But let's try to make some music where letters become sounds:

$$
\begin{aligned}
& \text { dishjkj! - } \\
& \text { yhdidshjkj } \\
& \text { eesh - dishjkj! - } \\
& \text { yhdidshjkj - shjkjyhdid } \\
& \text { dishjkj, dishjkj, dishjkj, dishjkj, dishjkj! } \\
& \text { shjkjyhdid, dishjkj — } \\
& \text { dishjkj, dishjkj, shjkjyhdid, yhdidshjkj } \\
& \text { dishjkj, dishjkj, dishjkj, dishjkj, dishjkj! }
\end{aligned}
$$

I can get better at this.

$$
\begin{aligned}
& \text { dtttishjkjjkjshjkjyhdidyhdidshjkj } \\
& \text { dtttishjkjjkjshjkjyhdidyhdidshjkj dishjkjjkjshjkjyhdidyhdidshjkj } \\
& \text { dttishjkjjkjshjkjyhdidyhdidshjkj dddddtishjkjjkjshjkjyhdidyhdidshjkj } \\
& \text { ddddttishjkjjkjshjkjyhdidyhdidshjkj dtttttishjkjjkjshjkjyhdidyhdidshjkj } \\
& \text { dishjkjjkjshjdidshjkj - xxissd, dtttishjkjjkjshj } \\
& \text { - dttishjkjjkdddjshj - xxissd - dttishjkjjkxjshj }
\end{aligned}
$$

34 Computer as text as computer 2, John Richards, 2016. The 'Alex' voice was used. 
dishjkjjkjsxxissd - dishjkjjkjshj

xxissd

dddddddkjjkjshjkjy - xxissd, dddddddkjjkjshjkjy

You are now beginning to work me out! If you try letter combinations that contain vowels and consonants, then perhaps I can even make sound poetry!

\section{Virtuosity is in the listening}

Closely allied to the idea of musical instrument is the notion of virtuosity. There is an expectation that a performer, in some way, will master their instrument. The instrument is compliant to the will of the performer. A 'bad' instrument is regarded as difficult to control, awkward to hold, and inferior in tone; so how does a player become a virtuosity of a 'bad' instrument? There are more conundrums when considering virtuosity within the field of DIY electronic music. Leaving aside issues of access and the implications of this in relation to virtuosity - the hierarchy of musical instruments as discussed by Christopher Small in Musicking arguably does not exist in DIY electronic music where sound-making devices and instruments can be self-made relatively cheaply - a music of technology and DIY electronic music radically challenges established views of instrumental virtuosity. ${ }^{35}$ Firstly, an object-orientated approach to music making precludes an onus on the will of the player. The 'instrument' fights back: the player listens and responds to 'the instrument'. Like a carpenter carving a piece of wood, the grain of the wood has a resistance and has to be worked. Secondly, a music of things throws up the concept of an instrument that cannot be simply grasped - both mentally and physically. How can an instrument be mastered when that instrument is always evolving and never fixed in terms of its physical dimensions? Furthermore, machines and technology have brought automation. There is a long tradition of musical automata, the instruments/ sound devices of Percy Granger and Jean Tinguely being a couple of examples. But in the case of some electronic instruments that could be considered self-generating or where process and systems are evident, playing such instruments can resort to a switching on and off. Many self-built electronic devices and instruments have the capacity to play themselves. This leads to the question: where does virtuosity lie in such music? The answer to this question may lie in navigating the potential or relational aspects of the technology available to the performer; or, as I have discussed with Tim Shaw, virtuosity is in the listening. ${ }^{36}$

35 SMALL, Christopher. Musicking: the meanings of performing and listening. Hanover: University Press of New England, 1998, p. 69.

36 RICHARDS, John. oneknobtorule: Information Experience and Instrument Design [blog], 2015. https:// oneknobtorule.wordpress.com/ [accessed on 1/1/2017] 


\section{Bibliography}

BAILEY, Derek. Improvisation: its nature and practice in music. New York: Da Capo Press, 1993.

BOWERS, John, and ARCHER, Phil. Not Hyper, Not Meta, Not Cyber but Infra-Instruments. Proceedings of the International Conference on New Interfaces for Musical Expression (NIME), Vancouver, BC, Canada, 2005, p. 5-10.

BOWERS, John, RICHARDS, John, SHAW, Tim, et al. One knob to rule them all: reductionist interfaces for expansionist research. Proceedings of the International Conference on New Interfaces for Musical Expression (NIME), Brisbane, Australia, 2016, p. 433-438.

BRECHT, Bertolt, and WILLETT, John. Brecht on Theatre: The Development of an Aesthetic. New York: Hill and Wang, 1964.

CAGE, John, and CHARLES, Daniel. For the Birds: John Cage in Conversation with Daniel Charles. Boston, MA and London: Boyars, 1981.

CARDEW, Cornelius. Treatise Handbook. London: Peters, 1971.

DUNNE, Anthony. Hertzian Tales: Electronic Products, Aesthetic Experience, and Critical Design. The MIT Press: Cambridge, Massachusetts, 2005.

ENO, Brian, and SCHMIDT, Peter. Oblique Strategies: Over One Hundred Worthwhile Dilemmas. [Place of publication not identified]: [publisher not identified], 2001 [original publication 1975].

FASS, John, and RICHARDS, John. Dirty Electronics Weekender [blog], 2015. https:// dirtyelectronicsweekender.wordpress.com [accessed on 1/1/2017]

GAVER, William W., BEAVER, Jacob, and BENFORD, Steve. Ambiguity as a Resource for Design. Proceedings of the SIGCHI Conference on Human Factors in Computing Systems, 2003, vol. 5, no. 3, p. 233-240.

GLENDINNING, Chellis. Notes Toward a Neo-Luddite Manifesto. Utne Reader, March/April, 1990.

HALLNÄS, Lars, and REDSTRÖM, Johan. Slow Technology - Designing for Reflection. Personal and Ubiquitous Computing, 2001, vol. 5, no. 3, p. 201-212.

HONORÉ, Carl. In Praise of Slowness: How a Worldwide Movement is Challenging the Cult of Speed. San Francisco: HarperSanFrancisco, 2004.

LANDY, Leigh, and GRAEVENITZ, Antje von. 'I Make Technology Ridiculous': the Unusual Dialectics of June Paik. Avant Garde 7, 1992, p. 79-108.

MALINA, Frank J. Comments on Visual Fine Art Produced by Digital Computers. Leonardo, 1971, vol. 4, no. 3, p. 263-265.

NAKE, Frieder. There Should Be No Computer Art. Bulletin of the Computer Art Society, London, p. $18-21$.

PAIK, Nam J., CONNOR, Russell, and TOMPKINS, Calvin. Nam June Paik: Edited for Television [TV], Produced by the TV Lab at WNET/Thirteen (VTR series), 1975.

PAIK, Nam J., and YALKUT, Jud. Suite 212 [video]. New York: Electronic Arts Intermix [distributor], 1975 [re-edited 1977].

RICHARDS, John. Beyond DIY in Electronic Music. Organised Sound, 2013, vol. 18, no. 3, p. 274-281.

RICHARDS, John. oneknobtorule: Information Experience and Instrument Design [blog], 2015. https://oneknobtorule.wordpress.com/ [accessed on 1/1/2017]

RICHARDS, John. Shifting Gender in Electronic Music: DIY and Maker Communities. Contemporary Music Review, 2016, vol. 35, no. 1, p. 40-52. 
SALE, Kirkpatrick. Rebels against the future: the Luddites and their war on the Industrial Revolution: lessons for the computer age. Reading, Mass: Addison-Wesley Pub. Co., 1995.

SMALL, Christopher. Musicking: the meanings of performing and listening. Hanover: University Press of New England, 1998.

TOFFLER, Alvin. Future Shock. New York: Random House, 1970. 
